\title{
Segmented Copoly(ether-ester) Elastomers. Influence of Hard Segment Length and Substitution on Mesophase Formation ${ }^{\dagger}$
}

\author{
M. M. SonpatKi, K. Ravindranath, ${ }^{\dagger \dagger}$ and S. Ponrathnam* \\ Chemical Engineering Division, National Chemical Laboratory, \\ Pune-411008, India
}

(Received September 24, 1993)

\begin{abstract}
Syntheses of segmented copoly(ether-ester)s with (oxy-1,4-phenyleneoxycarbonyl1,4-phenylenecarbonyl)/(oxy-2-methyl-1,4-phenyleneoxycarbonyl-1,4-phenylenecarbonyl) (methyl series)/(oxy-2-chloro-1,4-phenyleneoxycarbonyl-1,4-phenylenecarbonyl) (chloro series) hard segments and poly(oxytetramethylene) soft segments, are reported. The methodology consisted of sequential melt condensation of terephthaloyl chloride with poly(oxytetramethylene)glycol $\left(\bar{M}_{n}=\right.$ 250) $[\mathrm{POTMG}]$ and hydroquinone (HQ)/methylhydroquinone (Me-HQ)/chlorohydroquinone (Cl-HQ). Hard segment length as well as substitution in core of hard segment were varied $(\mathrm{H}$ to $\mathrm{CH}_{3} / \mathrm{Cl}$ ) while maintaining the soft segment length constant. Copolymers were characterised for solubility behavior and by infrared spectroscopy, X-ray diffraction, DSC and polarising microscopy. Thermal properties were found to be dependent on average length of hard segment as well as on the type of substituent in the core of hard segment. All copoly(ether-ester)s are elastomeric at room temperature $\left(25^{\circ} \mathrm{C}\right)$. Some of the polymers synthesised exhibit thermotropic liquid crystalline behavior.
\end{abstract}

KEY WORDS Segmented Copoly(ether-ester)s / Hard Segment / Soft Segment / Random Copolymers / Thermotropic Liquid Crystalline Polymers / Mesophase / Thermotropic Elastomers / Thermal Properties /

Segmented thermoplastic elastomers ${ }^{1}$ based on copolyether-esters ${ }^{2,3}$ are well known. The physical characteristics are similar to cured elastomers while processing is akin to those used with rigid, glassy, or crystalline thermoplastics. The soft blocks in such thermoplastic copolymers, with alternating hard and soft blocks, impart elastomeric aptitude above its glass transition temperature, $T_{\mathrm{gs}}$ while rigid blocks are responsible for the mechanical properties by providing physical crosslinks and reinforcement sites at this temperature. However, incompatibility between soft and hard blocks generates a high melt viscosity while processing above the glass transition, $T_{\mathrm{gh}}$ (amorphous systems) or melting temperature, $T_{\mathrm{m}}$ (crystalline systems) of hard segments. This high melt viscosity can be depressed by incorporating hard blocks exhibiting thermotropicity, ${ }^{4}$ which tend to form microscopic domains with a preferential order. One could also visualize unusual rheological and crystallisation characteristics originating from the rubber like elasticity coupled with directional character of the mesogen. The liquid crystallinity will also influence molecular orientation after processing and finally the physical properties. A number of side chain liquid crystalline elastomeric systems have been synthesised. ${ }^{5-8}$ While work on main chain

+ NCL Communication No. 5872.

${ }^{\dagger \dagger}$ Present address: Department of Chemical Engineering, University of Wisconsin, Madison, WI 53706, U.S.A.

* To whom correspondence should be addressed. 
systems have been in progress for some time, it is only very recently that $\mathrm{Tsai}^{9}$ reported such a system with (alkylene 4,4'-bibenzoate) as mesogenic hard segment.

Here we present syntheses and properties of a new series of main chain thermoplastic elastomers wherein (oxy-1,4-phenyleneoxycarbonyl-1,4-phenylenecarbonyl)/(oxy-2-methyl1,4-phenyleneoxycarbonyl-1,4-phenylenecarbonyl) (methyl series) or (oxy-2-chloro-1,4phenyleneoxycarbonyl-1,4-phenylenecarbonyl) (chloro series) moieties act as hard segment and poly(oxytetramethylene) act as soft segment. The thermal properties of these copoly(ether-ester)s are presented and examined relative to structural variables. The effect of change in hard segment length as well as influence of substituent in the core of hard segment on the onset of thermotropicity are also discussed.

\section{EXPERIMENTAL}

Terephthalic acid (TA), hydroquinone (HQ), methylhydroquinone (Me-HQ), chlorohydroquinone (Cl-HQ) and poly(oxytetramethylene) glycol $\left(\bar{M}_{n}=250\right)$ (POTMG) were obtained from Aldrich Chemical Co. Inc., U.S.A. POTMG was dried overnight using activated $4 \AA$ and $3 \AA$ molecular sieves. HQ was recrystallised using hot water. Me-HQ was recrystallised using toluene whereas $\mathrm{Cl}-\mathrm{HQ}$ was recrystallised from chloroform. Terephthaloyl chloride (TPC) was synthesised from TA and thionyl chloride in petroleum ether and catalytic amount of dimethyl formamide. All apparatus were flame dried prior to use.

\section{POLYMER SYNTHESIS}

Freshly recrystallised TPC was reacted with POTMG $\left(\bar{M}_{n}=250\right)$ by slowly raising the reaction temperature from room temperature to $90^{\circ} \mathrm{C}$ over a period of three hours under dry and pure nitrogen atmosphere with stirring to form oligo ether-ester with acid chloride end groups. Hydrogen chloride (side product) liberated was scrubbed through aqueous alkali traps. Then HQ or Me-HQ or Cl-HQ was added to the reaction mixture containing oligo ether-ester and unreacted terephthaloyl chloride and temperature of the reaction mixture was raised gradually to $200^{\circ} \mathrm{C}$ over three hours under dry, pure nitrogen blanket with stirring and maintained at this temperature for a period of 30 minutes. Polymer obtained was purified by extraction with petroleum ether, washed sequentially with $5 \mathrm{wt} \%$ aqueous sodium bicarbonate, water, methanol, and dried to constant weight. The mole ratio of TPC/POTMG/ HQ was varied and substituent in the mesogenic core was changed from $\mathrm{H}$ to $\mathrm{CH}_{3} / \mathrm{Cl}$ as

Table I. Synthesis and soft segment thermal data of copoly(ether-ester)s obtained from terephthaloyl chloride, poly(oxytetramethylene)glycol 250 and hydroquinone

\begin{tabular}{|c|c|c|c|c|c|}
\hline \multirow{2}{*}{ Sample code } & \multirow{2}{*}{ Composition $^{\mathrm{a}}$} & \multirow{2}{*}{$|\eta|^{\mathrm{b}} / \mathrm{dl} \mathrm{g}^{-1}$} & \multirow{2}{*}{$T_{\mathrm{gs}}$ in ${ }^{\circ} \mathrm{C}$} & $\Delta C_{\mathrm{ps}}$ & \multirow{2}{*}{$\begin{array}{c}\text { Crystallinity } \\
\text { in } \%\end{array}$} \\
\hline & & & & $\mathrm{J} \mathrm{mol}^{-1} \mathrm{~K}^{-1}$ & \\
\hline TB1H50 & $1: 0.5: 0.5$ & 0.08 & -27.8 & 77.54 & 19.9 \\
\hline TB1H67 & $1: 0.33: 0.67$ & 0.10 & -25.5 & 160.37 & 34.9 \\
\hline TB1H75 & $1: 0.25: 0.75$ & $\mathrm{c}$ & -49.5 & 231.16 & 44.4 \\
\hline TB1H80 & $1: 0.20: 0.80$ & c & -48.2 & 104.60 & 48.9 \\
\hline TB1H83 & $1: 0.17: 0.83$ & c & -48.2 & 87.12 & 50.9 \\
\hline
\end{tabular}

a Molar ratio of terephthaloyl chloride: poly(oxytetramethylene)glycol 250 : hydroquinone.

b Intrinsic viscosity determined in 4-chlorophenol at $50^{\circ} \mathrm{C}$.

c Polymer insoluble in 4-chlorophenol.

d Calculated from room temperature X-ray diffraction. 
shown in Tables I and III.

\section{POLYMER CHARACTERIZATION}

The intrinsic viscosity, $[\eta]$, of methyl substituted polymer solutions in 4-chlorophenol at $50^{\circ} \mathrm{C}$ was measured using an $\mathrm{Ub}$ belohde viscometer. Infrared spectral measurements were made using potassium bromide (KBr) discs with a Shimadzu IR-470 and Perkin-Elmer 1600 series FT-IR spectrophotometer. X-Ray diffraction measurements were carried out using Philips PW 1730 Xray diffractometer with $\mathrm{Cu} K_{\alpha}$ target and nickel filter. Percent crystallinity was calculated by measuring the relative areas under the amorphous halo and crystalline peaks obtained from X-ray diffraction scan and taking a ratio of the area under the crystalline peaks to the total area [amorphous + crystalline]. Differential scanning calorimetric analysis were conducted using Mettler-4000 thermal analyser and DSC-30 cell. Temperature calibration was made by using Indium-Lead-Zinc standard and that of heat flow by using Indium standard. All thermal analyses were run at a rate of $10^{\circ} \mathrm{C} \mathrm{min}^{-1}$ under dry nitrogen. The sample mass were between 5 to $7 \mathrm{mg}$. Samples were analysed within two temperature ranges: between -75 to $50^{\circ} \mathrm{C}$ for soft segment glass transition temperature and between 50 to $350^{\circ} \mathrm{C}$ for hard segment transitions. Glass transition temperatures were taken at the temperature of half devetrification. Second heating and second cooling runs were also recorded after heating the samples above the first heating melting transition. Polarising microscopic studies were conducted under crossed polarised light with Leitz 350 hot stage coupled to Leitz Laborlux 12 Pols microscope. Photographs were taken using Leica wild MP S52/46 photoautomat system.

\section{RESULTS AND DISCUSSION}

Polymers with definite alternation of widely differing structural moieties are ideally suited to study the structural effects on properties. Such polymers with interesting property profiles are main chain thermotropic liquid crystalline polyesters. A variety of strategies have been established for the synthesis through low temperature solution polycondensation. Thus, nonmesogenic spacer is reacted either with (i) the mesogen having predetermined sequence resulting in sequentially ordered copolymers $^{10}$ or (ii) via staged addition technique without isolation/purification of mesogen so as to form sequentially random copolymers with alternating spacer and mesogenic groups. ${ }^{11}$ Reaction at high temperature leads to randomisation of comonomer sequence. ${ }^{12}$ The use of a oligomeric spacer with a distribution of lengths between the two functional groups, instead of a specific well defined one, results in lower melting polymers. This is ascribable to a break in the structural periodicity which disrupt packing efficiency. ${ }^{13}$ In sequentially ordered polymers thermal transitions occur at higher temperatures as compared to their random counterparts. ${ }^{12}$ It has also been well established that substituting hydrogen in the mesogenic core with bulkier groups/units may result in melt processable liquid crystalline polymers due to disruption in lateral packing. ${ }^{14}$ In random rigid rod flexible spacer type main chain copolymers thermotropic character has been observed at high dilutions of mesogens. ${ }^{15,16}$

This concept can be extended to form segmented thermotropic liquid crystalline copoly(ether-ester) elastomers. We have synthesised random segmented copoly(ether-ester) elastomers by resorting to stage addition melt condensation technique. In the first series (Table I) composition was varied such that soft segment length remains constant whereas that of hard segment increases. In other series (Table III) for some compositions, methyl/ chlorohydroquinone was used with similar mole ratios. Thus, terephthaloyl chloride was reacted first with flexible poly(oxytetrameth- 


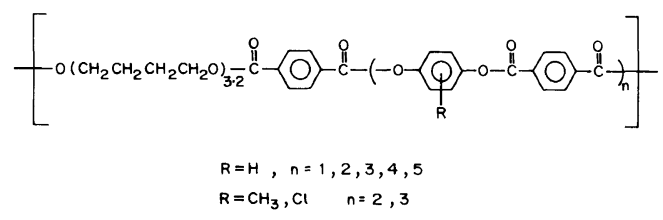

Figure 1. Global structure of copoly(ether-ester).

ylene) glycol spacer having a narrow but distinctive distribution of lengths. The resulting mixture of prepolymer and unreacted terephthaloyl chloride was reacted subsequently with hydroquinone or substituted hydroquinone. Polymers obtained in 95-98\% yield by this method are pale yellow. Global structure of hard and soft segment are as shown in Figure 1. Mole ratios of POTMG:HQ were varied such that average " $n$ " in Figure 1 varies from 1 to 5 with increase in HQ mol\%.

The synthesised copoly(ether-ester)s were thoroughly investigated for their solubility characteristics. Except for the polymer with $50 \mathrm{~mol} \%$ of POTMG, which is partially soluble in chloroform, all other polymers were found to be insoluble in common organic solvents. Increase in phase segregation in thermoplastic elastomers is known to decrease the solubility due to strong physical interaction between hard segments. ${ }^{17}$ This and the presence of long, rigid hard segment may be the reasons for the observed solubility behavior in our polymers. However, unsubstituted series of polymers having higher mol\% of POTMG (upto 33\%) and all methyl substituted polymers were found to be soluble in 4-chlorophenol. Intrinsic viscosity estimated in 4-chlorophenol were very low $\left(\sim 0.10 \mathrm{dlg}^{-1}\right)$. Similar low intrinsic viscosity values have been reported for ordered liquid crystalline polymers with poly(oxyethylene) glycol spacer. ${ }^{13}$ No specific rationale has been ascribed for the same. Lower intrinsic viscosities may be due to solvent induced hydrolytic slicing of polymers. Indeed infrared spectra of such copoly(ether-ester) dissolved in 4-chlorophenol shows shift of original ester carbonyl group from 1725 to $1680 \mathrm{~cm}^{-1}$

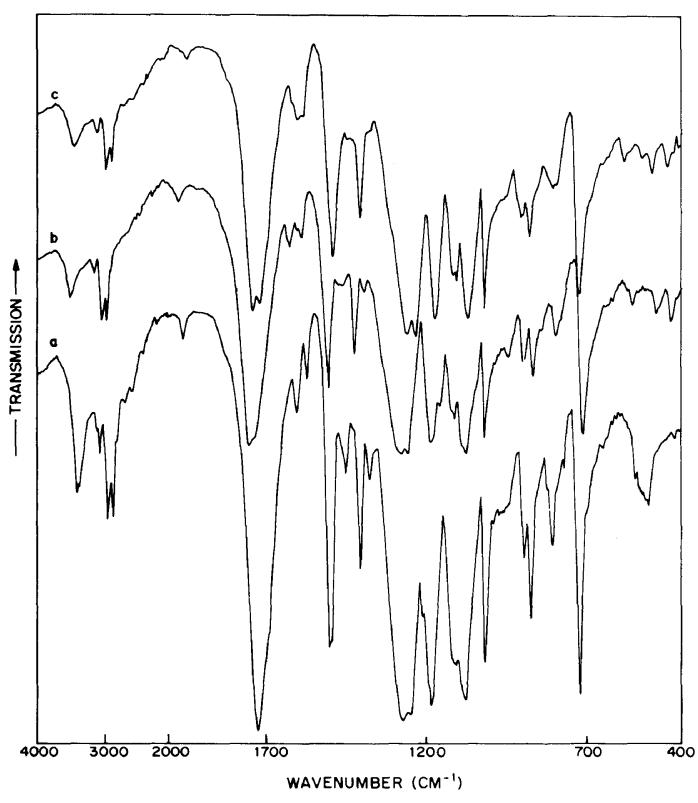

Figure 2a. Infrared spectra of copoly(ether-ester)s: a) TB1H75, b) TB1MH75, and c) TB1CH75 (for sample codes see Table 1).

corresponding to acid carbonyl.

Typical infrared spectras of unsubstituted, methyl and chloro substituted copoly(etherester)s with $25 \mathrm{~mol} \%$ POTMG are shown in Figure 2a. The absorptions at 2960 and $2880 \mathrm{~cm}^{-1}$ (aliphatic C-H stretching) correspond to methylene groups. Peaks between $1600-1500 \mathrm{~cm}^{-1}$ correspond to aromatic $\mathrm{C}=\mathrm{C}$ stretching whereas those between 1300 $1100 \mathrm{~cm}^{-1}$ correspond to skeletal $-\mathrm{C}-\mathrm{O}-\mathrm{C}-$ stretchings in ester/ether linkages. For unsubstituted polymers a single, broad peak at $1725 \mathrm{~cm}^{-1}$ corresponding to ester carbonyl was observed. However, FT-IR spectra of this sample shows that this peak can be deconvoluted into two peaks corresponding to hard and soft segment ester carbonyl (Figure 2b). In substituted copoly(ether-ester)s resolution of ester groups are indicated by appearance of two peaks, one at $1738 \mathrm{~cm}^{-1}$ corresponding to hard segment and other at $1718 \mathrm{~cm}^{-1}$ corresponding to soft segment. This points to the formation of block copoly(ether-ester). Also 


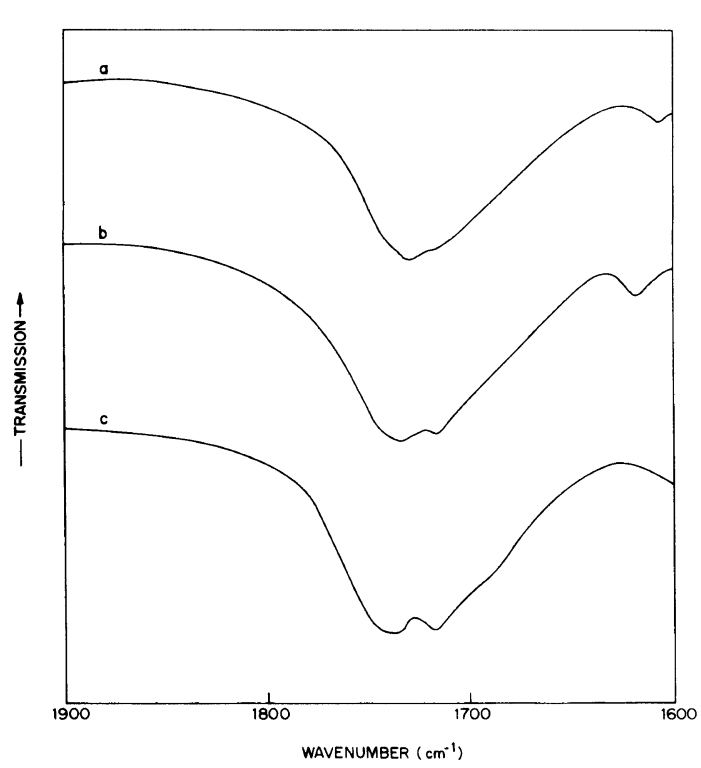

Figure 2b. FT-IR spectra (amplified) of copoly(etherester)s: a) TB1H75, b) TB1MH75, and c) TB1CH75 (for sample codes see Table I) showing ester carbonyl region.

the resolution between two ester groups was less for methyl substituted copoly(ether-ester), as compared to chloro substituted system. Amplified FT-IR spectra within 1900-1600 $\mathrm{cm}^{-1}$ range showing ester carbonyl region is presented in Figure 2b.

Percent crystallinity of unsubstituted copoly(ether-ester)s obtained from X-ray diffraction at $25^{\circ} \mathrm{C}$ increases with hard segment length as seen in Table I. Crystallinity is depressed over similar molar ratios with methyl or chloro substitution as observable in Table III. This points to disruption in lateral packing of molecules which arises from the presence of substituents. The decrease is more pronounced in chloro substituted polymers. However, crystallinity increases with increase in length of hard segment (rigidity) in both substituted systems.

Insolubility of polymers in common organic solvents negates any possibility of estimating molecular weights of these polymers. However, all polymers were synthesised by identical methodology. Thus, it is quite reasonable that the molecular weights of all polymers will be similar to be compared for their thermal characteristics. Further, in main chain liquid crystalline polymers $T_{\mathrm{g}}, T_{\mathrm{m}}$ as well as $T_{\mathrm{i}}$ increase with molecular weight and then level off at certain molecular weight. ${ }^{18}$ In highly phase separated polymers of comparable molecular weights and having a constant soft segment length, soft segment glass transition ( $\left.T_{\mathrm{gs}}\right)$ will remain constant whereas $T_{\mathrm{m}}$ will change with average hard segment length as it is a property of the hard segment. In the present series of segmented polymers (unsubstituted as well as substituted), with a constant soft segment length (POTMG 250), $T_{\mathrm{gs}}$ remains insensitive to change in composition and substitution on the hard segment. However, $T_{\mathrm{m}}$ does vary along the series (as discussed further) with increase in concentration of hard segment. The above observations indicate that differences in the phase transition of hard segments must occur as a consequence of variation in composition. Hence, thermal data obtained can be well related with compositional variation, eventhough molecular weights of polymers are indeterminable.

Differential scanning calorimetry (DSC) of unsubstituted copoly(ether-ester)s shows two distinctly order transitions, a second order glass transition below room temperature corresponding to soft segment $\left(T_{\mathrm{gs}}\right)$ and first order multiple endotherms above room temperature pertaining to hard segment. Soft segment glass transition curves are shown in Figure 3 and corresponding heat capacitychange $\left(\Delta C_{\mathrm{ps}}\right)$ are reported in Table I. All polymers show very low values of $T_{\mathrm{gs}}$ indicating their high flexibility (elastomeric character). These are similar to thermoplastic elastomer like hytrel which have $T_{\mathrm{gs}}$ in between $-30^{\circ} \mathrm{C}$ to $-60^{\circ} \mathrm{C}^{19}$ Such low values in the present system indicates highly phase separated nature of these copolymers. This may be due to a limited solubility of hard segments in the soft phase or an increased tendency for hard segments to remain in the hard segment 




Figure 3. Soft segment glass transition curves of unsubstituted copoly(ether-ester)s: a) TB1H50, b) TB1H67, c) TB1H75, d) TB1H80, and e) TB1H83 (for sample codes see Table I).



Figure 4. The photograph of copoly(ether-ester) TB1H50 at $128^{\circ} \mathrm{C}$ showing phase separation (magnification $\times 320$ ) (for sample code see Table I).

domains thereby resulting in superior domain organisation which prevents mixing of hard and soft segments. This phase separation well below the melting point of hard segment is also revealed from polarising microscopy as shown in Figure 4. For polymers TB1H50 and TB1H67 some what higher $T_{\mathrm{gs}}\left(\sim-30^{\circ} \mathrm{C}\right)$ at

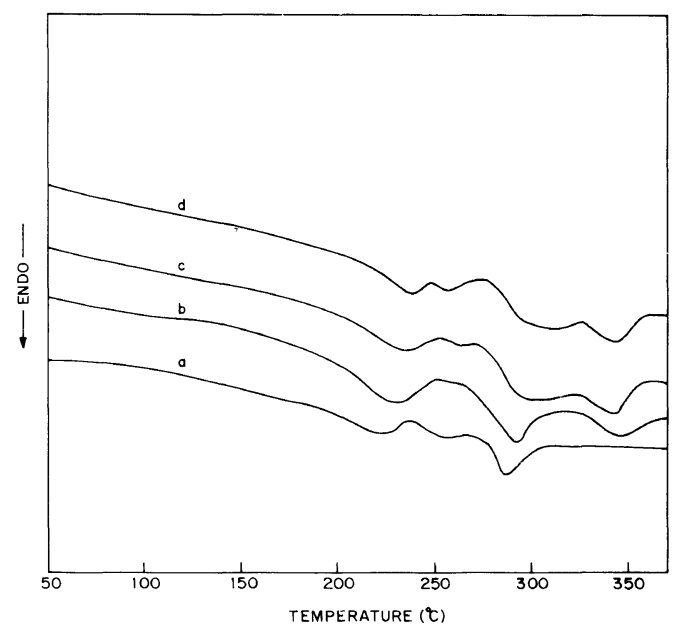

Figure 5. The DSC second heating curves of unsubstituted copoly(ether-ester)s: a) TB1H67, b) TB1H75, c) TB1H80, and d) TB1H83 (for sample codes see Table I).

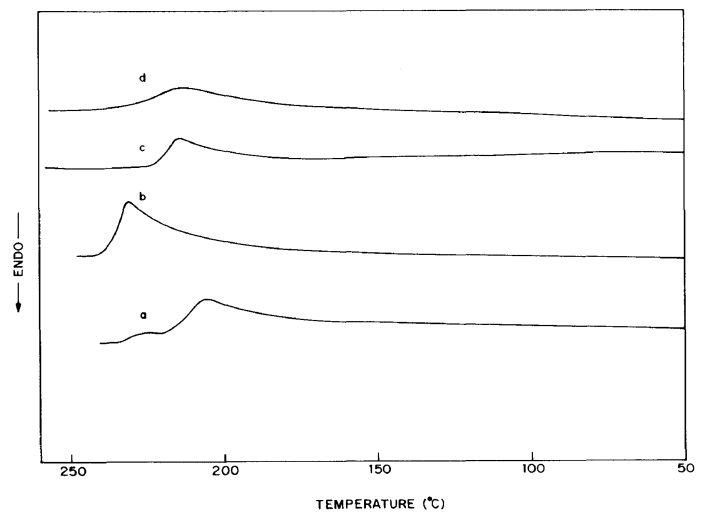

Figure 6. The DSC second cooling curves of unsubstituted copoly(ether-ester)s: a) TB1H67, b) TB1H75, c) TB1H80, and d) TB1H83 (for sample codes see Table I).

lower concentration of hard segment units must be due to penetration of short length hard segments in the rubbery phase. This also points to an restricted influence of hard segment on the flexibility of soft segment. All samples were heated just beyond first (lower) major melting transition and cooled back to room temperature so as to create uniform thermal history. Subsequent second heating DSC thermograms are shown in Figure 5 and concurrent thermal data was reported in Table II. The correspond- 
ing exotherms during second cooling cycle are shown in Figure 6. There was no difference in transition temperature in the first and second heating cycles. However, heating samples beyond higher temperature transition leads to degradation. This was observable from smaller exotherms and endotherms during succeeding cooling and second heating cycles. Thermal degradation was also visually observed by opening the DSC sample pan after the first heating cycle recorded till well beyond the first transition. Presence of oxy groups in the copolymer promotes such degradation.

Multiple endotherms have been previously observed for various copolyesters. ${ }^{20,21}$ These originate from one or a combination of reasons such as differing crystal structure/type and perfection, molecular weight distribution and/ or crystal reorganisation. Annealing treatments did not affect the multiple endotherms observable in our copoly(ether-ester)s. This clearly indicates that these are not due to differing crystal perfections or molecular weight distribution. Also, the multiple endotherms were independent on heating rate which rules out the possibility of crystal reorganisation. In random copoly(ether-ester)s, hard segment lengths are always an average based on feed ratios of monomers. Thus, at any given copolymer composition, moieties with hard segment length shorter or longer than the calculated average length will always be present in the sample. Thermoplastic elastomer such as hytrel, consist of terephthaloyl: butane diol [PTMT] hard segments. Variation in average hard segment length within a particular sample in that system would not influence the thermal properties as dramatically as observed in the present system consisting of wholly aromatic, highly rigid terephthaloyl: hydroquinone hard segments. Eventhough hard segment, with flexible moieties (butane diol), having lengths longer than calculated average length in hytrel will have higher melting temperature, its effect may not be vigorous enough so as to result either in entirely different melting endotherm or crystal type. The occurrence of multiple endotherms in the present system (Figure 5) is thus due to different crystal type ascribable to hard segment domain populations/lengths. The higher temperature transition is due to hard segments having lengths longer than the average. This is discussed further in terms of variation in hard segment length with monomer composition. In Table II, the peak temperature of endotherms during the second heating is seen to shift to higher side with increase in hard segment length. This is due to increase in rigidity.

Table II. Second heating and second cooling DSC data of copoly(ether-ester)s obtained from terephthaloyl chloride, poly(oxytetramethylene)glycol 250 and hydroquinone

\begin{tabular}{ccccc}
\hline & \multicolumn{2}{c}{$T^{\mathrm{a}}$ in ${ }^{\circ} \mathrm{C}$} & $\Delta H$ & \multicolumn{1}{c}{$\Delta H_{\mathrm{c}}{ }^{\mathrm{c}}$} \\
\cline { 3 - 4 } & & $\mathrm{kJ} \mathrm{mol}^{-1}$ & $T_{\mathrm{c}}^{\mathrm{b}}$ in ${ }^{\circ} \mathrm{C}$ & $\mathrm{kJ} \mathrm{mol}^{-1}$ \\
\hline TB1H50 & $214.2^{\mathrm{d}}$ & $2.26^{\mathrm{d}}$ & - & $0.17,2.26$ \\
TB1H67 & $221.7,254.7,281.7$ & $2.12,0.49,0.95$ & $228.2,204.9$ & 3.33 \\
TB1H75 & $236.3,294.6,343.0$ & $2.45^{\mathrm{e}}$ & 230.3 & 1.93 \\
TB1H80 & $236.4,300.5,344.2$ & $2.09^{\mathrm{e}}$ & 214.2 & 1.69 \\
\hline
\end{tabular}

a Peak temperature corresponding to multiple endotherms.

b Crystallisation temperature.

c Enthalpy change of crystallisation for lower temperature transition.

d Transition temperature and enthalpy change obtained during first heating.

e Enthalpy change of melting obtained for lower temperature transition. 
Melting transition observed during first heating cycle for polymer with $50 \mathrm{~mol} \%$ of hydroquinone (TB1H50) could not be traced back during second heating. Also no exotherm was observed during first cooling cycle. The smaller length and lower concentration of hard segment results in their inability to aggregate together into crystalline regions. Polarising microscopy does not display any liquid crystalline textures at this temperature.

Further increase in hard segment length results in multiple melting transitions during second heating observable from Figure 5 for copoly(ether-ester)s with $67 \mathrm{~mol} \% \mathrm{HQ}$ (TB1H67). As discussed earlier, such transitions originate from varying hard segment domain population/length. Melting of crystallites was also confirmed from polarising microscopy observations. However, neither transition leads to liquid crystallinity. Thus, hard segment length may not be sufficient so as to produce mesophase order in this polymer. The cooling exotherm corresponding to first major melting transition is as shown in Figure 6.

Polarising microscopy observation of polymer with $75 \mathrm{~mol} \% \mathrm{HQ}$ (TB1H75), indicates liquid crystalline nature corresponding to lower temperature transition obtained during second heating DSC cycle (Figure 5). However, with further heating no variation in morphology was visually observed relating to higher DSC endotherms. The appearance of these transitions may be attributed to solid $\rightarrow$ solid transition arising from moieties having longer hard segment length or very small soft segment proportion. Photograph showing a fine granulated texture of birefringent domains is reproduced in Figure 7. Such a "fine grain" texture is characterised as unspecific variety of smectic C mesophase. ${ }^{22,23}$

Enthalpy change $(\Delta H)$ of melting relating to lower transition decreases (Table II) with further increase in hard segment length, eventhough transitions shift to higher temperature. This is due to enrichment of noncrystallising longer hard segments in the system. Po-



Figure 7. The photograph of $\mathrm{TB} 1 \mathrm{H} 75$ at $285^{\circ} \mathrm{C}$ (magnification $\times 320$ ) (for sample code see Table I).

larising microscopy indeed shows very small proportion of meltable crystallites $(\mathrm{C} \rightarrow \mathrm{LC})$.

Above results are further supported from second cooling data (Table II). Enthalpy change of crystallisation $\left(\Delta H_{c}\right)$ increases as hard segment length increases, with 67 to $75 \mathrm{~mol} \%$ of HQ. This shows concurrent increase in crystallinity of the copoly(etherester) with the length of hard segment. However in copolymers, with further increase in hard segment length (above $75 \mathrm{~mol} \%$ of HQ), a weaker exotherm (Figure 6) is observed due to generation of very small proportion of crystallisable (or meltable) hard segments. These polymers (TB1H80 and TB1H83) in turn consist of a high proportion of longer hard segment blocks which are incapable of melting.

Thus, decrease in mole percent of HQ below 75 in this series of unsubstituted random copoly(ether-ester)s results in shorter hard segment lengths which are insufficient to produce mesophase order and infusible blocks are formed with increase in $\mathrm{HQ}$ above $75 \mathrm{~mol} \%$. Further, no transition to isotropic state was detectable from either DSC or polarising microscopy due to degradation prior to isotropisation.

In substituted copoly(ether-ester)s $T_{\mathrm{gs}}$ was observed well below room temperature $\left(\sim-50^{\circ} \mathrm{C}\right)$ indicating their elastomeric character as shown in Figure 8 and presented in Table III. It can be seen from the table that all $T_{\mathrm{gs}}$ values are 
insensitive to variation in hard segment length as well as nature of substituent $(\mathrm{Me}$ or $\mathrm{Cl})$ in the hard segment. This indicates high phase separated nature of these copolymers. However, hard segment displays second order glass transition instead of first order melting



Figure 8. Soft segment glass transition curves of substituted copoly(ether-ester)s: a) TB1MH67, b) TB1MH75, c) TB1CH67, and d) TB1CH75 (for sample codes see Table III). transition. This points to steric hindrance by substituents against the formation of 3dimensional order in these polymers. Further, $T_{\mathrm{gh}}$ was not observable in second heating cycles conducted after differing cooling rates and annealing conditions. The order initially present could not be recovered, once the sample was melted. Hence, first heating DSC curves for hard segments are shown in Figure 9 and corresponding thermal data are reported in Table III. In both methyl and chloro

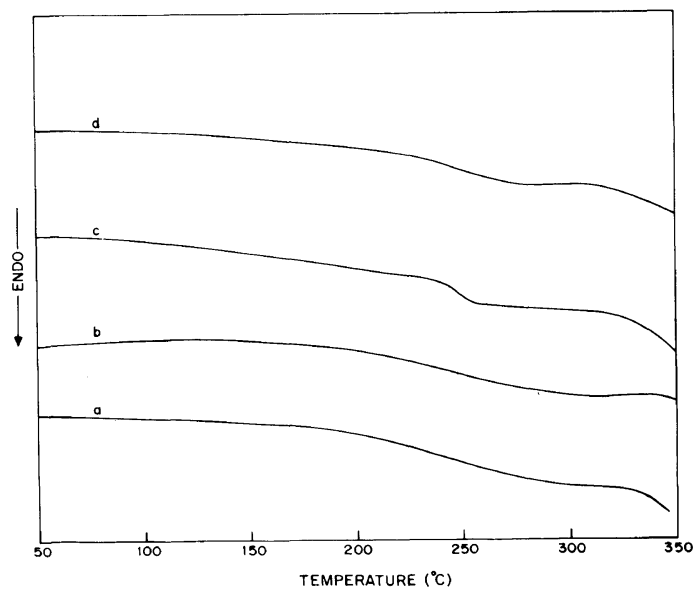

Figure 9. Hard segment glass transition curves of substituted copoly(ether-ester)s: a) TB1MH67, b) TB1MH75, c) TB1CH67, and d) TB1CH75 (for sample codes see Table III).

Table III. Synthesis and thermal data ${ }^{a}$ of copoly(ether-ester)s obtained from terephthaloyl chloride, poiy(oxytetramethylene)glycol 250 and methyl/chlorohydroquinone

\begin{tabular}{|c|c|c|c|c|c|c|c|}
\hline \multirow{2}{*}{ Sample code } & \multirow{2}{*}{ Composition } & \multirow{2}{*}[\eta]{$^{\mathrm{b}} / \mathrm{dl} \mathrm{g}^{-1}$} & \multirow{2}{*}{$T_{\mathrm{gs}}$ in ${ }^{\circ} \mathrm{C}$} & \multirow{2}{*}{$\frac{\Delta C_{\mathrm{ps}}}{\mathrm{J} \mathrm{mol}^{-1} \mathrm{~K}^{-1}}$} & \multirow{2}{*}{$\begin{array}{c}T_{\mathrm{gh}} \\
\text { in }^{\circ} \mathrm{C}\end{array}$} & \multirow{2}{*}{$\frac{\Delta C_{\mathrm{ph}}}{\mathrm{J} \mathrm{mol}^{-1} \mathrm{~K}^{-1}}$} & \multirow{2}{*}{$\begin{array}{c}\text { Crystallinity } \\
\text { in } \%\end{array}$} \\
\hline & & & & & & & \\
\hline TB1MH67 & $1: 0.33: 0.67^{\mathrm{c}}$ & 0.19 & -47.6 & 109.44 & 242.9 & 221.84 & 18.1 \\
\hline TB1MH75 & $1: 0.25: 0.75^{\mathrm{c}}$ & 0.15 & -48.4 & 111.43 & 253.8 & 125.72 & 27.7 \\
\hline TB1CH67 & $1: 0.33: 0.67^{\mathrm{d}}$ & e & -45.4 & 238.29 & 248.2 & 95.94 & 11.4 \\
\hline ТВ1CH75 & $1: 0.25: 0.75^{\mathrm{d}}$ & $\mathrm{e}$ & -45.4 & 207.71 & 256.0 & 78.27 & 14.8 \\
\hline
\end{tabular}

a Subscripts " $s$ " and " $h$ " indicate soft and hard segment properties respectively.

b Intrinsic viscosity determined in 4-chlorophenol at $50^{\circ} \mathrm{C}$.

c Molar ratio of terephthaloyl chloride: poly(oxytetramethylene)glycol 250: methylhydroquinone.

d Molar ratio of terephthaloyl chloride: poly(oxytetramethylene)glycol 250 : chlorohydroquinone.

e Polymer is insoluble in 4-chlorophenol.

f Calculated from room temperature X-ray diffraction. 
substituted copoly(ether-ester)s, $T_{\text {gh }}$ shifts to higher temperature with increase in hard segment length. The $T_{\mathrm{gh}}$ of chloro substituted copolymers are higher than those of methyl substituted copolymers of similar composition due to enhanced packing arising from intermolecular dipolar interactions.

A comparison of thermal properties of substituted $V_{\mathrm{s}}$ unsubstituted copoly(etherester)s of similar composition leads to following observations. The $T_{\mathrm{gh}}$ in substituted copolymers are higher than the $T_{\mathrm{m}}$ (first major melting temperature) in unsubstituted copoly(ether-ester)s. Also, copoly(ether-ester)s containing $33 \mathrm{~mol} \%$ POTMG but with substitution in the rigid segment (TB1MH67 and TB1CH67) exhibit liquid crystallinity as revealed by polarising microscopy, while unsubstituted copoly(ether-ester) of similar mole percent of POTMG (TB1H67) does not show liquid crystallinity. No transition corresponding to isotropic state was detected during first heating cycle in DSC for substituted series of copolymers as well, possibly due to very small change in heat capacity. However, visually degradation of polymers at higher temperature was observed by opening the DSC sample pan. Presence of large number of oxy units in the copolymer decreases the thermal stability.

In low molecular weight main chain liquid crystalline random copolymers ${ }^{18}$ glass transition temperature, melting point, clearing point and mesophase thermal stability are depressed by substitution in the mesogenic core. In contrast, in our random copoly(ether-ester)s substitution in the mesogenic core disrupts effectively lateral molecular packing to induce thermotropic character rather than lowering the transition temperature.

Both series of substituted copoly(etherester)s were observed for their liquid crystalline behavior on polarising microscope coupled with hot stage. The soft segment is already in viscoelastic state. Crystallites originating from hard segment could be observed embeded in



(a)

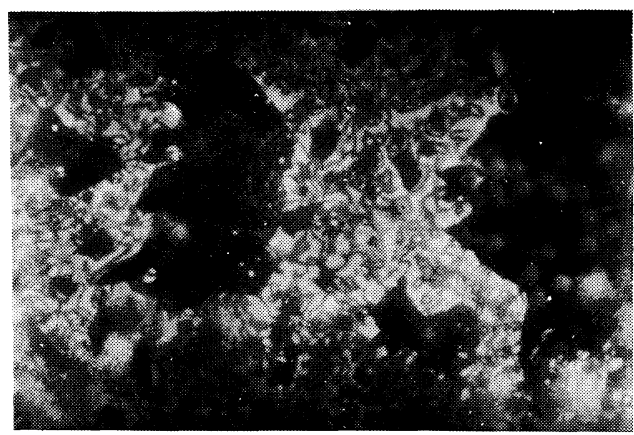

(b)

Figure 10. The photographs of TB1MH67: (a) at $288^{\circ} \mathrm{C}$ and (b) after shearing at $288^{\circ} \mathrm{C}$ (magnification $\times 320$ ) (for sample code see Table III).

elastomeric matrix at temperatures below $T_{\mathrm{gh}}$. Both series of substituted copoly(ether-ester)s exhibit typical nematic textures similar to that observed in alkyl substituted thermotropic polyesters. ${ }^{24}$ Figure 10a shows intense nematic texture for methyl substituted copoly(etherester) (TB1MH67). No apparent difference in texture was observed within the series with increase in hard segment length. Only onset of liquid crystalline phase shifts towards higher temperature side. However, difference were noted between the two series on shearing the sample between coverslip and glass plate. For methyl series black filamentous texture can be observed (Figure 10b) on shearing vis-à-vis intensely colored threaded schlieren texture for chloro series (Figure 11a). The frozen-in nematic texture can be observed when the sample was cooled back to room temperature 


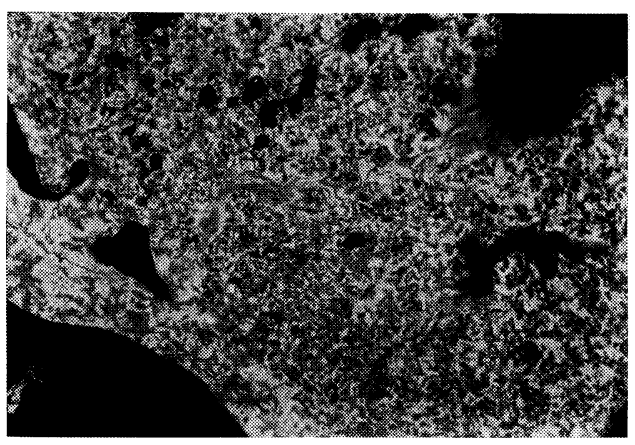

(a)

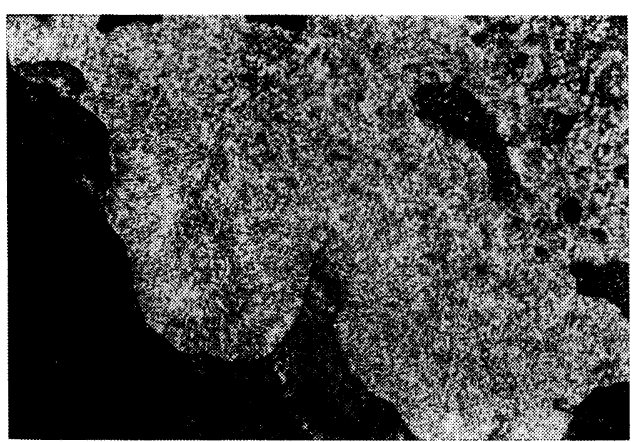

(b)

Figure 11. The photographs of $\mathrm{TB} 1 \mathrm{CH} 67$ (a) after shearing at $291^{\circ} \mathrm{C}$ and (b) frozen liquid crystalline texture at room temperature (magnification $\times 320$ ) (for sample code see Table III).

(Figure 11b). Isotropic transition was obscured by thermal degradation (above $315^{\circ} \mathrm{C}$ ) and hence could not be detected.

\section{CONCLUSION}

Segmented elastomeric copoly(ether-ester)s of constant flexible segment length were synthesised by varying (i) length of hard segment and (ii) substituent in the core of hard segment $\left(\mathrm{CH}_{3} / \mathrm{Cl}\right)$. Intense phase separation of hard and soft segments were indicated in DSC thermograms by the presence of well separated low temperature glass transition (below room temperature) and high temperature melting (or $T_{\mathrm{g}}$ for substituted series) transition (above $200^{\circ} \mathrm{C}$ ) corresponding to soft and hard seg- ments respectively. Increase in the length of hard segment resulted in (i) shift in transition temperature to higher temperature and (ii) change from thermoplastic to thermotropic and finally to infusible systems. Similarly, substitution in the core of hard segment of thermoplastic elastomer by methyl or chloro groups induced thermotropic liquid crystalline characteristics.

Acknowledgment. We thank Mdm. C. Noel, PCSM, ESPCI, France for very fruitful discussions and Dr. J. P. Jog, National Chemical Laboratory, Pune for providing POM facility. One of us (M.M.S.) would like to thank UGC, New Delhi for research fellowship.

\section{REFERENCES}

1. N. R. Legge, G. Holden, and H. E. Schroeder, "Thermoplastic Elastomers," Hanser Publishers, New York, 1987.

2. E. I. du Pont de Nemours and Co., U.S. 3,651,014 (1972); [Chem. Abstr., 79, 19440w (1973)].

3. E. I. du Pont de Nemours and Co., U.S. 3,784,520 (1974); [Chem. Abstr., 80, 48949v (1974)].

4. C. K. Ober, J.-I. Jin, and R. W. Lenz, Adv. Polym. Sci., M. Gordon, Ed., Springer-Verlag, Berlin, 59, 103, (1984).

5. H. Finkelmann, H. J. Kock, and G. Rehage, Makromol. Chem., Rapid Commun., 2, 317 (1981).

6. H. Finklemann and W. Gleim, "Side Chain Liquid Crystal Elastomers," in "Side Chain Liquid Crystal Polymers," C. B. McArdle, Ed., Blackie and Sons Ltd., Great Britain 1989, p 285.

7. F. J. Davis, A. Gilbert, J. Mann, and G. R. Mitchell, J. Polym. Sci., Polym. Chem., 28, 1455 (1990).

8. N. R. Barnes, F. J. Davis, and G. R. Mitchell, Mol. Cryst., Liq. Cryst., 168, 13 (1989).

9. H. B. Tsai, C. Lee, and N. S. Chang, Polym. J., 24, 157 (1992).

10. A. Y. Bilbin and D. N. Piraner, Makromol. Chem., 192, 201 (1991).

11. A. Delvin and C. K. Ober, Polym. Bull., 20, 45 (1988).

12. J.-I. Jin, H. Chang, B. W. Jo, K. Y. Sung, and C. S. Kang, Makromol. Chem., Macromol. Symp., 33, 97 (1990).

13. G. Galli, E. Chiellini, C. K. Ober, and R. W. Lenz, Makromol. Chem., 183, 2693 (1982).

14. S. Antoun, R. W. Lenz, and J.-I. Jin, J. Polym. Sci., Polym. Chem., 19, 1901 (1981). 
15. R. S. Ghadage, S. Ponrathnam, and V. M. Nadkarni, Polym. Commun., 29, 116 (1988).

16. A. K. Rath and S. Ponratham, J. Appl. Polym. Sci., 49, 391 (1993).

17. Y. Camberlin and J. P. Pascault, J. Polym. Sci., Polym. Phys., 22, 1835 (1984).

18. V. Percec and H. Nava, J. Polym. Sci., Polym. Chem., 25, 405 (1987).

19. K. B. Wagener, in "Polymer Handbook," 3rd ed, J. Brandup and E. H. Immergut, Ed., Wiley-Interscience, New York, N.Y., 1989, pV-107.
20. J. C. Stevenson and S. L. Cooper, J. Polym. Sci., Polym. Phys., 26, 953 (1988).

21. E. Marsano, U. Salati, and B. Valenti, Polymer, 34, 1232 (1993).

22. V. P. Shibaev and N. A. Plate, Adv. Polym. Sci., M. Gordon, Ed., Springer-Verlag, Berlin, 60/61, 173 (1984).

23. D. Demus and L. Richter, "Textures of Liquid Crystals," Verlag Chemie, New York, N.Y., 1978.

24. Q. F. Zhou and R. W. Lenz, J. Polym. Sci., Polym. Chem., 21, 3313 (1983). 